\title{
Report of a case of surgical ciliated cyst in the left maxillary sinus
}

\author{
Amirhossein Pakravan, ${ }^{a}$ Shima Nafarzadeh ${ }^{b^{*}}$
}

`Oral and Maxillofacial Surgery department, Mazandaran University of Medical Sciences, Sari, Iran.
bOral and Maxillofacial Pathology department, Babol University of Medical Sciences, Babol, Iran.
Correspondence to Shima Nafarzadeh (email: shima.nafar2004a2yahoo.com).
(Submitted: 28 March 2017 - Revised version received: 16 April 2017 - Accepted:22 April 2017 - Published online: 26 June 2017)

Surgical ciliated cyst happens as a delayed complication in the maxillary sinus, and is more frequent in Asia in comparison with Western countries. We report a case of surgical ciliated cyst in maxillary sinus in a male patient after 30 years of surgery for sinusitis treatment. The patient had swelling and pain in the region, and his radiographic views showed a cystic lesion. Incisional biopsy was performed and surgical ciliated cyst was reported as diagnosis. Then, Enucleation with curettage was performed for him as treatment.

Keywords surgical ciliated cyst, maxilla, sinus

\section{Introduction}

Surgical ciliated cyst is a type of true epithelial lined antral cysts, which arises from sinonasal mucosa and gland. It is believed to occur after sinus trauma and surgery because of a separation, which occurs in the sinus lining that forms a cystic cavity lined by epithelium. Even a difficult extraction can damage the floor of sinus and lead to the cyst formation.

Surgical ciliated cyst was first described in 1927 in Japan by Kubo. ${ }^{2}$ Very limited cases with this entity have been reported in English articles. ${ }^{3}$ The lesion is more frequent in Japan. ${ }^{4}$ Its prevalence in patients with 5 to 49 years of age who had a previous history of maxillary sinus surgery was estimated to be more than $20 \%$ in Japan. Postoperative maxillary cyst, traumatic ciliated cyst, and paranasal cyst were also used as synonyms for the lesion. ${ }^{1,3}$ Surgical ciliated cyst is considered as an inflammatory and destructive lesion in sinus region, which is developed after orthognathic and Caldwell-Luc radical antrostomy.

Clinical view of the lesion resembles tumoral lesion and causes vestibular and palatal expansion. Moreover, fistula formation was noted in some cases. ${ }^{6}$ Few research reported the lesion in mandible after orthognathic surgery, and some research reported its occurrence in mandible after genioplasty and osteocartilaginous graft. ${ }^{1,7}$ If a non-vital tooth is seen in the area, the lesion resembles a radicular cyst. ${ }^{8}$ Here, we report a case of surgical ciliated cyst occurred in the left maxillary sinus after 30 years of sinus surgery.

\section{Case Report}

A 49-year-old male patient came to the oral and maxillofacial surgeon clinic in Sari, Iran presenting with the chief complaint of a swelling and pain in the left side of his upper jaw. The patient's past medical history revealed a surgery in his maxillary sinuses 30 years ago for treatment of sinusitis. His familial and medical history was not noticeable. He also did not show smoking or alcohol consumption habit in past years. On extra-oral examination, tenderness of the area was detected.

Radiographic examination showed a well-defined radiolucency in his left maxillary sinus, extending to the maxillary ridge and between premolar and molar roots, measuring about $4 \times 1.5 \mathrm{~cm}$ in diameter. Swelling of buccal cortex with destruction in some areas was seen. In addition to that, a similar lesion with smaller size was obvious in his right maxillary sinus (Figs. 1 and 2). Root canal therapy for premolar teeth and re-treatment for involved molar were done to eliminate dental inflammation source. His pain was relieved but swelling was persistent after 1 month.

Incisional biopsy for the left sinus mass and excisional biopsy for the right sinus were performed. Histopathologic examination demonstated a cystic lesion covered by ciliated pseudo-stratified columnar epithelium (Figs. 3 and 4). Mucus cells in the lining and mucus in the lumen space were detected. Chronic inflammatory cells infiltration was found in the cyst connective tissue wall.

Based on the clinical and microscopic findings, surgical ciliated cyst was made as diagnosis (Figs. 3 and 4). The patient underwent excisional surgery for the left side lesion with complete curettage. He was asked for follow up sessions, and no recurrence was evident after 3 months.

\section{Discussion}

Surgical ciliated cyst is believed to develop after a mucosal epithelial remaining during a bone-healing phase after an osteotomy in the area. ${ }^{3}$ The exact prevalence of this cyst is unknown in Iran, but it is estimated to have a 3-20\% incidence in Japan, perhaps due to the high prevalence of sinusitis in this country and also the preference of surgery to antibiotic therapy there. ${ }^{9}$ The cyst is detected as a unilocular or multilocular radiolucency with the capacity to expand into the canine fossa and also to the nasal wall of sinus. Aggressive behavior of the cyst has been occasionally obsereved..$^{10}$ In cases that involved teeth are nonvital, it can mimic a Radicular cyst. ${ }^{8}$ It is important to differentiate a surgical ciliated cyst from sinus pseudocysts or mucoceles, which have similar linings, and sometimes are related to trauma. ${ }^{11}$ Cyst formation duration varies from 6 month to 49 years. ${ }^{12} \mathrm{~A}$ surgical ciliated cyst that developed at 5 years after maxillary advancement surgery, with significant upper displacement of the sinus floor, communication with nasal fossa, and palatine bone perforation was reported by Amin et al. ${ }^{4}$ Our patient mentioned a history of surgery 30 years ago. This period may show the slow process of cystic changes and its inaggressive nature. 


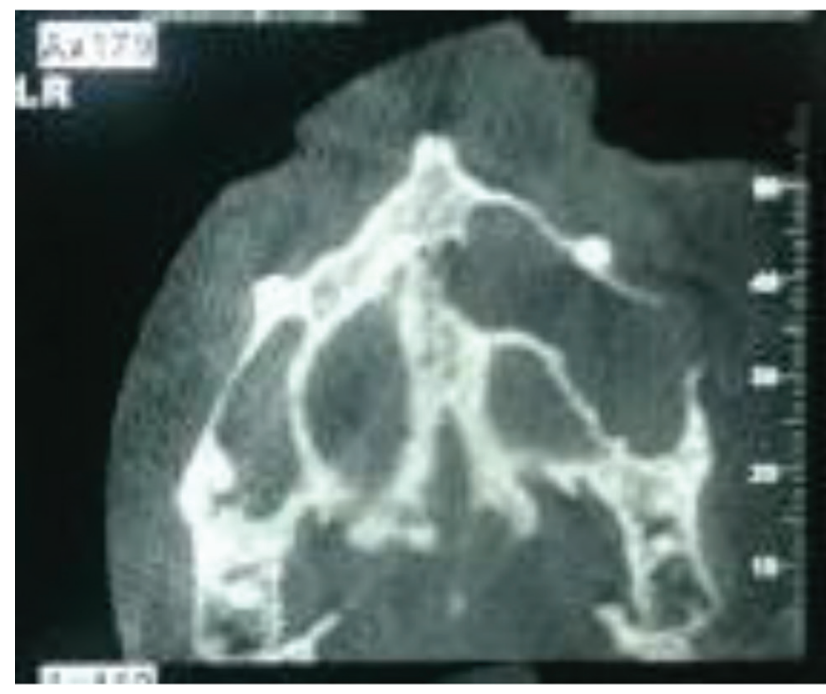

Fig 1. CT scan shows a well-defined radiolucent lesion in the left maxillary sinus.

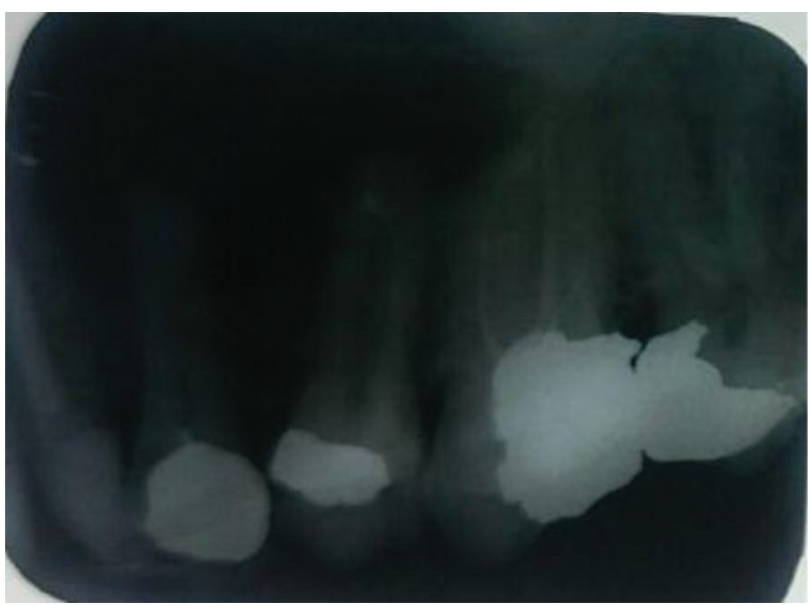

Fig 2. Periapical radiograph shows a destructive lesion involving the apical area of premolar and molar teeth.

The histopathologic feature of the cyst showed typical characteristics of the cyst consist of a connective tissue wall lined by ciliated pseudo-stratified columnar epithelium and areas of mucous cells. Maruyama et al. evaluated 360 ciliated cysts histologically and found that $66 \%$ of them showed pseudo-stratified ciliated epithelium, 28\% transition epithelium, and 6\% squamous epithelium. Goblet cells were present in all cysts except in areas with squamous epithelium. The number of goblet cells was observed to be related to the inflammatory cells infiltration. ${ }^{13}$ Ciliated cells can be seen in other cysts such as odontogenic

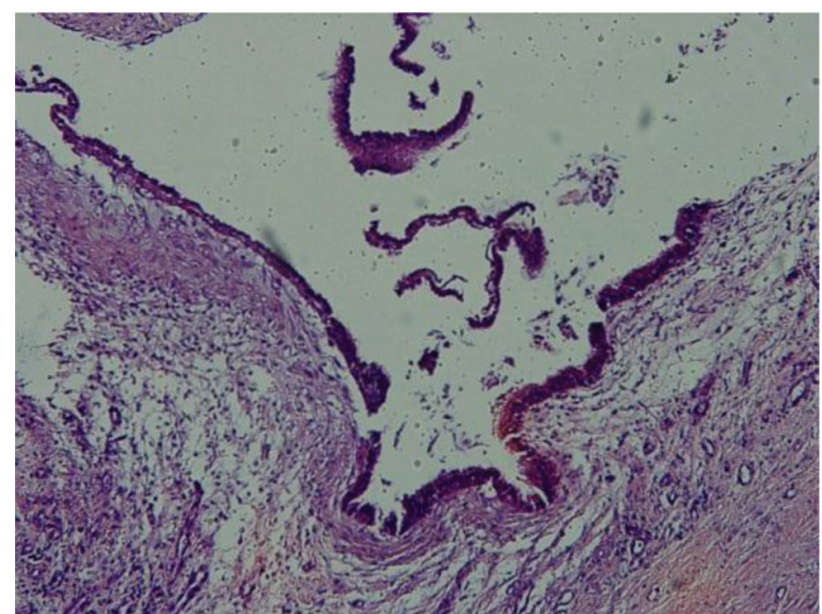

Fig 3. Histopathologic view shows a cystic lesion lined by ciliated pseudo-stratified columnar epithelium $(\times 40)$.

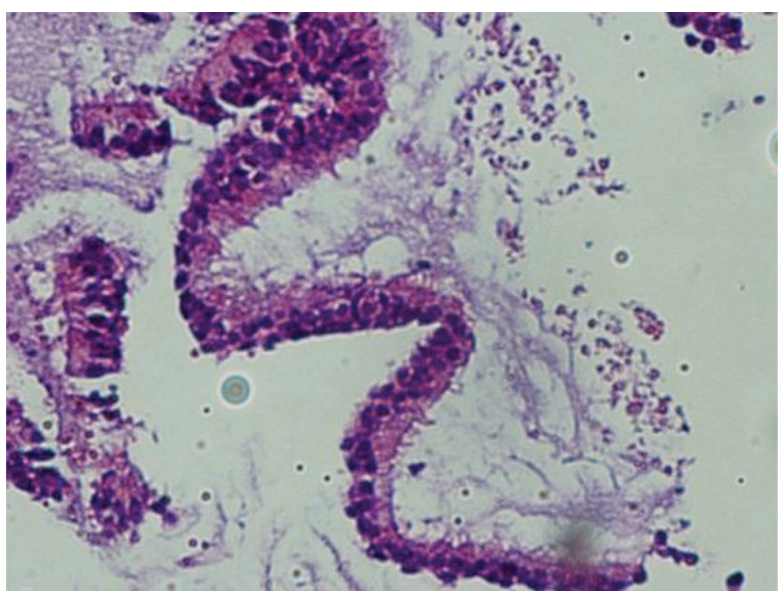

Fig 4. Microscopic view shows ciliated pseudo-stratified columnar epithelium $(\times 100)$.

keratocyst, however, the epithelial characteristics of the latter will help to be distinguished. ${ }^{1}$

The treatment was discussed by Yoshikawa et al. in 1982. They proposed enucleation or marsupialisation of the cyst. The marsupialisation was the preferred method for unilocular cysts with a thin wall or large cysts with extensive bone perforation. ${ }^{15}$

Precise studies are necessary to determine the incidence of surgical ciliated cyst in Iran. Since surgical ciliated cyst of the maxilla is believed to result from entrapment of the epithelium of sinus in the maxilla during surgical procedure, a preventive measure such as careful suturing and patient followup is highly recommended.

\section{References}

1. Neville BW, Damm DD, Allen CM, Bouquat JE. Oral \& maxillofacial pathology, 4th ed. India: Saunders; 2016. pp. 295-296.

2. Kubo I. A buccal cyst occurred after a radical operation of the maxillary sinus. Z F Otol Tokyo. 1927:3:896-897.

3. Cano J, Campo J, Alobera MA, Baca R. Surgical ciliated cyst of the maxilla. Clinical case. Med Oral Patol Oral Cir Bucal. 2009;14 E361-4

4. Bartnik W, Bartnik-Krystalska A. Postoperative maxillary cyst. Otolaryngol Pol. 2004:58:641-643.

5. Amin M, Witherow $H$, Lee $R$, Blenkinsopp P. Surgical ciliated cyst after maxillary orthognathic surgery: report of a case. J Oral Maxillofac Surg. 2003;61:138-141

6. Sugar AW, Walker DM, Bounds GA. Surgical ciliated (postoperative maxillary) cysts following mid-face osteotomies. Br J Oral Maxillofac Surg. 1990;28:264-267.

7. Anastassov GE, Lee $H$. Respiratory mucocele formation after augmentation genioplasty with nasal osteocartilaginous graft. J Oral Maxillofac Surg. 1999:57:1263-1265. 
8. Leung YY, Wong WY, Cheung LK. Surgical ciliated cyst may mimic radicular cysts or residual cysts of maxilla: Report of 3 cases. J Oral Maxillofac Surg. 2012;70:264-269.

9. Kaneshiro S, Nakajima T, Yoshikawa Y, Iwasaki H, Tokiwa N. The postoperative maxillary cyst: report of 71 cases. J Oral Surg. 1981;39:191-198.

10. Pe MB, Sano K, Kitamura A, Inokuchi T. Computed tomography in the evaluation of postoperative maxillary cysts. J Oral Maxillofac Surg. 1990;48:679-684.

11. Thio D, Phelps PD, Bath AP. Maxillary sinus mucocele presenting as a late complication of a maxillary advancement procedure. J Laryngol Otol. 2003;117:402-403.

12. Lockhart R, Ceccaldi J, Bertrand JC. Postoperative maxillary cyst following sinus bone graft: report of a case. Int J Oral Maxillofac Implants. 2000;15:583-586.
13. Maruyama M, Onodera K, Ooya K. A histopathological and lectinhistochemical study of the lining epithelium in postoperative maxillary cysts. Oral Dis. 2002;8:241-248.

14. Yamazaki M, Cheng J, Nomura T, Saito C, Hayashi T, Saku T. Maxillary odontogenic keratocyst with respiratory epithelium: a case report. J Oral Pathol Med. 2003;32:496-498.

15. Yoshikawa Y, Nakajima T, Kaneshiro S, Sakaguchi M. Effective treatment of the postoperative maxillary cyst by marsupialization. J Oral Maxillofac Surg. 1982:40:487-491.

16. Fernandes KS, Gallottini MHC, Felix VB, Santos PSS, Nunes FD. Surgical ciliated cyst of the maxilla after maxillary sinus surgery: a case report. Oral Surg. 2013;6:229-233.

This work is licensed under a Creative Commons Attribution-NonCommercial 3.0 Unported License which allows users to read, copy, distribute and make derivative works for non-commercial purposes from the material, as long as the author of the original work is cited properly. 